\title{
Analisa Posisi Peletakkan Baut terhadap Gaya Geser pada Sambungan Plat Baja
}

\author{
Sudjatmiko*, I Made Sunada, Yanuar Wibisono \\ Jurusan Teknik Mesin, Universitas Merdeka Malang \\ Jln. Puncak Jaya No 1 Malang (65122) \\ *Corresponding author email: sudjatmiko@unmer.ac.id
}

\section{INFORM ASI ARTIKEL ABSTRACT}

Diterima: 14 September 2020

Direvisi: 14 September 2020

Disetujui: 10 Oktober 2020

Tersedia online: 15 Oktober 2020

DOI:

doi.org/10.26905/jtmt.v16i2.4789

\begin{abstract}
Research on analysis the effect of positioning the use of bolts on the connection process between the two steel plates against the other steel plates to determine the magnitude of the bolt torque moment and the magnitude of the force. The connection of the steel plate components where the joints are used are able to with stand shear forces, pressure and torsion. The research objective was to determine the effective placement of the bolt position and the distance of the load on the vertical and horizontal bolt position to the magnitude of the torque due to compression and the fracture model. Data collection was carried out in several tests of changes in the placement of the bolt joints, including the position of the bolts with three angles, in the vertical and horizontal position of the bolts. The findings of the placement of the three-angle bolt position at 2-4-11 the shear force experienced a shift / fracture of the bolt greater than the shear force that occurred in the horizontal and vertical bolts position, with a pressure of 92.66 bar (torsion moment 108,342 $\mathrm{kg}$-mm). Testing the position of the three-angle bolt at 2-6-10 where the vertical bolt was broken with a pressure of 65.33 bar ( torque moment $76.401 \mathrm{~kg}$ $\mathrm{mm})$. The three-angle bolt placement test at 6-7-8 where the horizontal bolt was fractured at a pressure of $55.33 \mathrm{bar}$ (torque moment $64,701 \mathrm{~kg}-\mathrm{mm}$ ). Comparison of the placement of the bolts in the position of three angles of the shear force between the vertical and horizontal positions, the shear forces experience the greatest shift / fracture of the bolts in the vertical position. The loading distance affects the amount of shear force that occurs on the bolt. the farther the loading distance, the greater the shear force that occurs.
\end{abstract}

Keywords: Steel plate connection, torsion moment

Penelitian analisa pengaruh pemosisian penggunaan baut pada proses penyambungan antar kedua plat baja satu terhadap plat baja lain untuk mengetahui besarnya momen torsi baut dan besarnya gaya. Penyambungan komponen plat baja posisi letak sambungan digunakan mampu menahan gaya geser, tekanan, dan puntiran. Tujuan penelitian untuk mengetahui peletakkan posisi letak baut yang efektif dan jarak pembebanan pada peletakkan posisi baut vertikal dan horisontal terhadap besarnya momen torsi akibat penekanan dan model patahan. Pengambilan data dilakukan beberapa pengujian perubahan peletakkan posisi sambungan baut di antaranya posisi peletakan baut dengan tiga sudut, pada posisi baut vertikal dan horizontal. Hasil temuan peletakkan posisi baut tiga sudut pada 2-4-11 gaya geser mengalami pergeseran/patahan baut lebih besar dibandingkan gaya geser yang terjadi pada posisi baut horisontal dan vertikal, dengan tekanan 92,66 bar (momen puntir $108.342 \mathrm{~kg}-\mathrm{mm}$ ). Pengujian posisi baut tiga sudut pada 2 -6-10 letak baut vertikal baut mengalami patah dengan tekanan 65,33 bar (momen puntir $76.401 \mathrm{~kg}-\mathrm{mm}$ ). Pengujian peletakkan posisi baut tiga sudut pada 6-7-8 letak baut horisontal mengalami patah pada tekanan 55,33 bar (momen puntir $64.701 \mathrm{~kg}-\mathrm{mm}$ ). Perbandingan peletakkan baut pada posisi tiga sudut gaya geser antara posisi vertikal dengan horisontal, gaya geser mengalami pergeseran/patahan baut yang paling besar terjadi pada posisi vertikal. Jarak pembebanan mempengaruhi besarnya gaya geser yang terjadi pada baut. semakin jauh jarak pembebanan maka semakin besar gaya geser yang terjadi.

Kata kunci : Sambungan plat baja, momen puntir 


\section{Pendahuluan}

Sambungan baut merupakan jenis sambungan yang menerima gaya tekan dan gaya geser yang besar. Dengan menentukan posisi letak baut dan susunan yang sesuai untuk jenis sambungan yang digunakan, maka perlu dilakukan pengujian terhadap posisi letak baut yang dominan digunakan dalam konstruksi sambungan plat baja.Secara umum baut akan mengalami beberapa bentuk pembebanan yang terjadi seperti: Beban puntir,beban geser dan beban tarik, tergantung dari beban yang diterima sehingga baut akan mengalami kerusakan atau patahan. Hasil kajian [1] analisis dinamik dengan diagram Godman dapat dilihat bahwa kegagalan yang terjadi adalah karena lelah (patah fatique) karena tegangan yang bekerja berada diluar grafik, ini sesuai dengan bentuk patahan yang terjadi pada baut. Menurut kajian [2] sambungan mur baut dengan metode sambungan plat baja, menggunakan ukuran baut M12 dengan variasi baut ring plat, dari 2 variasi yang digunakan, hasil variasi tambahan plat dari dengan variasi ring lebih kuat terhadap tekanan. Semakin tebal tambahan, maka semakin kuat sambungan untuk menahan gaya tekan. Menurut kajian [3] jarak jari-jari (r) ke titik pusat tidak mempengaruhi tegangan geser yang terjadi pada baut dan besarnya tekanan yang diberikan oleh beban akan mempengaruhi tegangan geser yang dialami oleh baut. Semakin besar tekanan semakin besar tegangan geser dan sebaliknya. Baut yang putus geser tergantung dari besarnya gaya penekanan dan baut akan putus lebih dekat ke pusat penekanan[5].Permasalahan pengaruh besarnya momen torsi pada perubahan letak posisi sambungan baut terhadap jarak pembebanan arah vertikal dan horisontal, akibat gaya geser. Tujuan penelitian untuk mengetahui peletakkan posisi letak baut yang efektif dan jarak pembebanan pada peletakkan posisi baut vertikal dan horisontal terhadap besarnya momen torsi akibat penekanan dan model patahan.

\section{Metode Penelitian}

\subsection{Diagram alir penelitian}

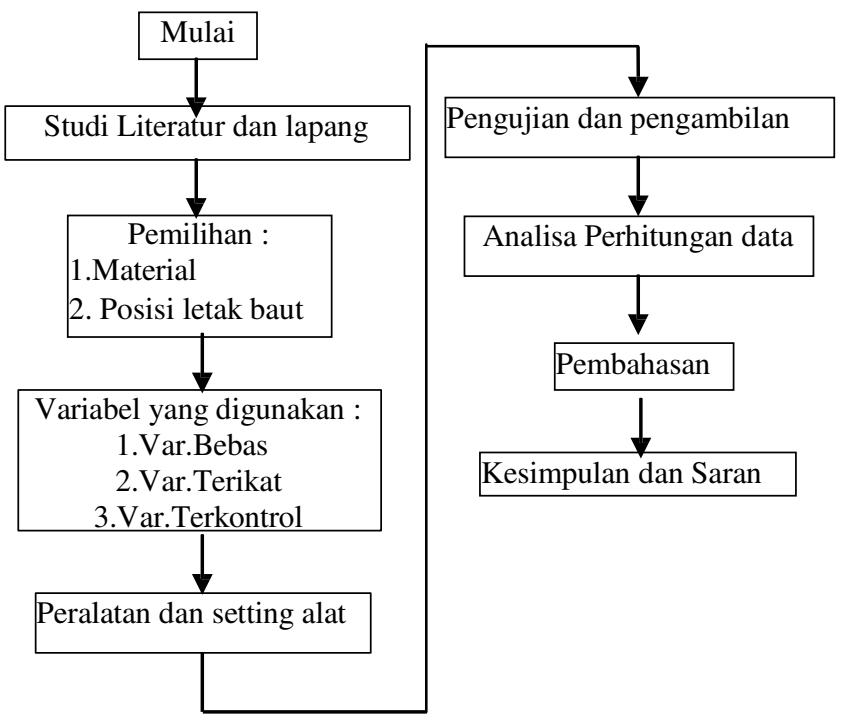

Gambar 1. Diagram alir penelitian

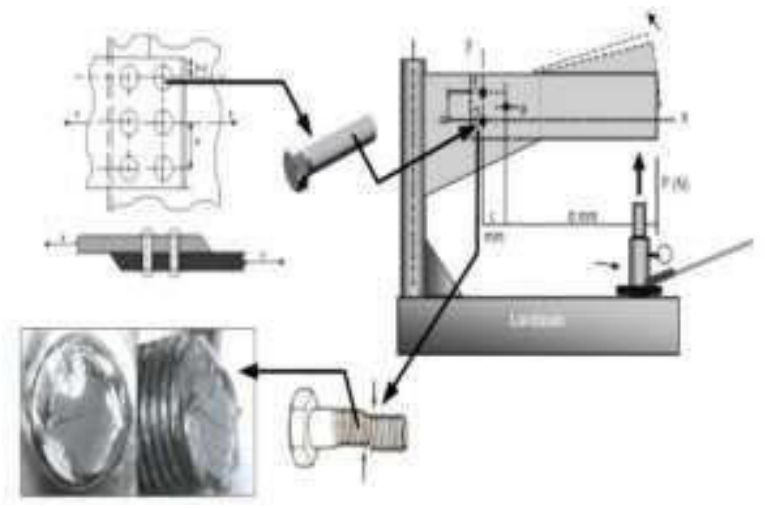

Gambar 2. Setting peralatan Uji pematah baut untuk pengambilan data [5]

Tabel 1. Rancangan pengujian pengambilan data

\begin{tabular}{llllllll}
\hline No & Posisi baut & A & B & C & D & E & F \\
\hline L1 & $2-6-10$ & & & & & & \\
L2 & $6-7-8$ & & & & & & \\
L3 & $2-4-11$ & & & & & & \\
\hline
\end{tabular}

Keterangan :

$\mathrm{A}=$ Luas Penampang baut $\left(\mathrm{mm}^{2}\right) \quad \mathrm{D}=$ Gaya dongkrak $(\mathrm{kg}-\mathrm{f})$

$\mathrm{B}=$ Titik berat $(\mathrm{X}, \mathrm{Y})(\mathrm{mm}) \quad \mathrm{E}=$ Momen puntir $(\mathrm{kg}-\mathrm{mm})$

$\mathrm{C}=$ Tekanan dongkrak (bar) $\quad \mathrm{F}=$ Nomor baut putus

\subsection{Alat dan Bahan yang digunakan}

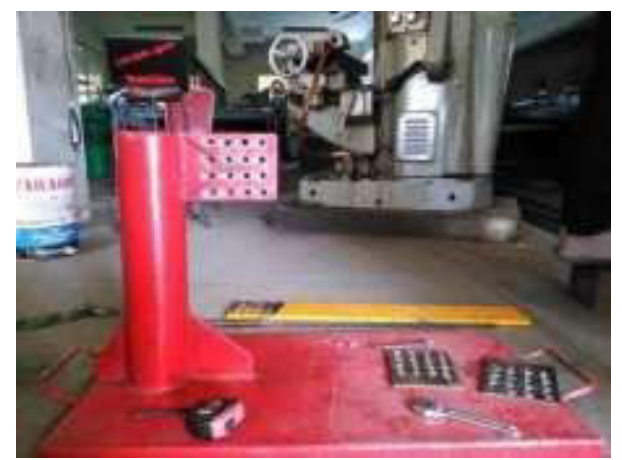

Gambar 3. Alat eksperimen pematah baut

Sumber : Laboratorium proses produksi JTM Unmer Malang

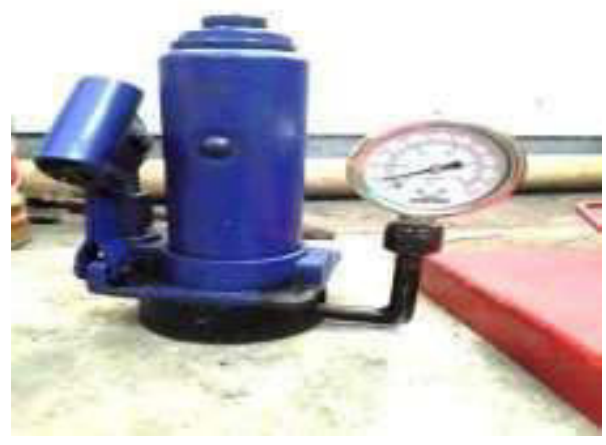

Gambar 4. Dongkrak

Sumber : Laboratorium proses produksi JTM Unmer Malang 


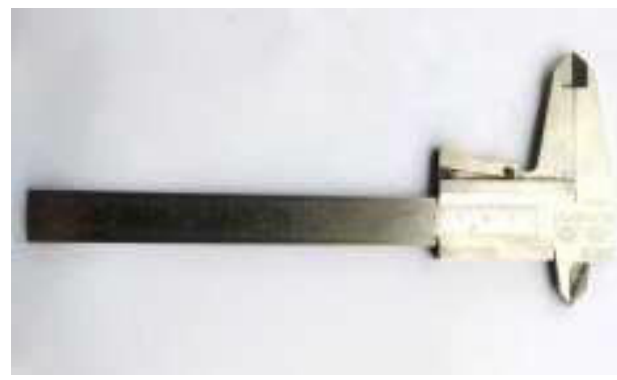

Gambar 5. Jangka Sorong

Sumber : Laboratorium proses produksi JTM Unmer Malang

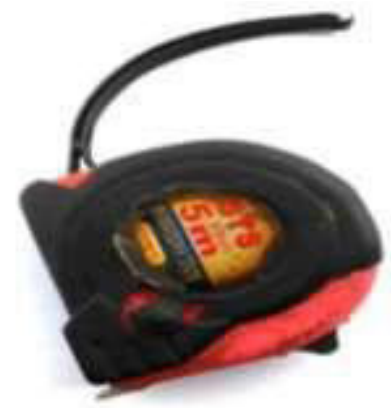

Gambar 6. Roll Meter

Sumber : Laboratorium proses produksi JTM Unmer Malang

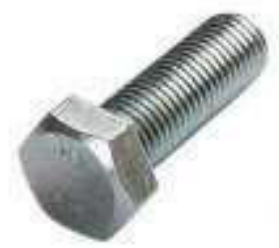

Gambar 7. Baut [4]

\subsection{Variabel penelitian}

$>$ Variabel bebas

-Posisi letak jarak antar baut

> Varikberat terikata masing-masing letak posisi baut

-Tegangan bahan baut $(\boldsymbol{\sigma})$

-Model patahan baut

$>$ Variabel terkontrol

-Tekanan pada dongkrak (P.bar)

-Jarak titik berat

\subsection{Tempat dan Waktu Penelitian}

> Laboratorium proses produksi JTM Unmer Malang

$>$ Waktu : Desember 2017 Desember 2017

\section{Hasil dan Pembahasan}

Pada bagian ini akan disajikan beberapa data yang menunjukkan hasil pengujian pada spesimen. Hasil penelitian posisi pengujian letak baut disajikan pada Gambar 8,9,10 dan 11. Hasil penelitian juga disajikan dalam bentuk tabel agar mempermudah dalam pembacaan data.

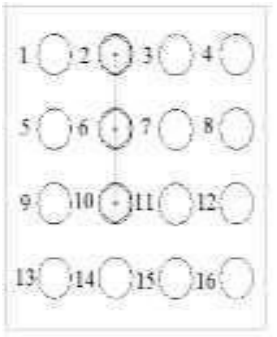

(a)

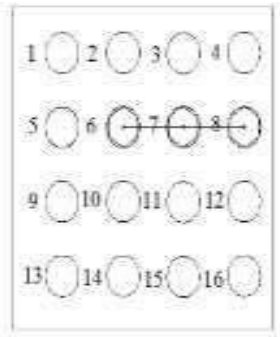

(b)

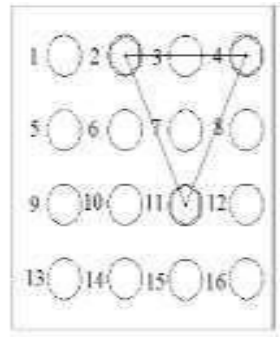

(c)
Gambar 8 konfigurasi posisi letak baut [5]

Gambar 8 menyajikan konfigurasi posisi letak baut untuk pengambilan data dilakukan dengan posisi :

(a). Vertikal,(b).horisontal dan (c). sudut segi tiga (three angle)

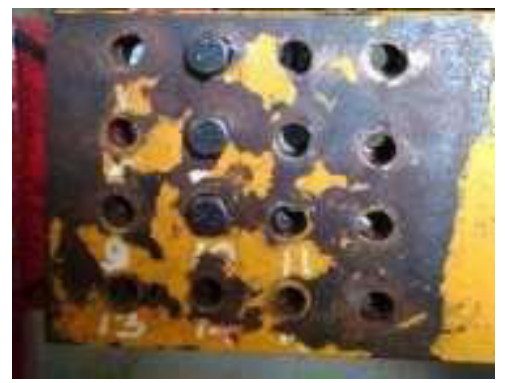

Gambar 9. Posisi baut vertikal 2-6-10

Sumber: Laboratorium proses produksi JTM Unmer Malang

Pada Gambar 9 menjajikan pengujian posisi baut vertikal 2-6-10 menggunakan 3 baut, dengan titik berat x.160;y.260. Pada posisi vertikal besarnya diameter dan jarak berpengaruh pada kekakuan, sehingga deformasi terjadi sebelum baut tersebut patah [7].

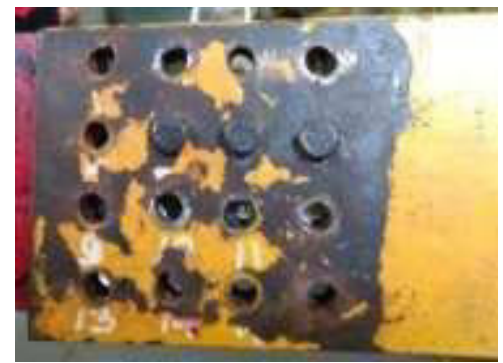

Gambar 10. Posisi baut vertikal 6-7-8 Sumber: Laboratorium proses produksi JTM Unmer Malang

Pada Gambar 10 menyajikan pengujian posisi baut horisontal 6- 7-8 menggunakan 3 baut dengan titik berat x.260;y.260. Pada posisi horisontal besarnya diameter dan jarak berpengaruh pada kekakuan, sehingga deformasi terjadi sebelum baut tersebut patah [7]. 


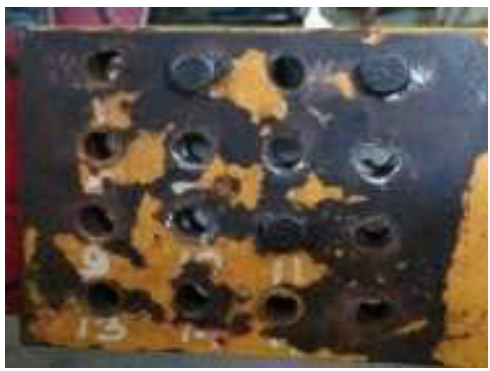

Gambar 11. Posisi baut vertikal 2-4 -11

Sumber: Laboratorium proses produksi JTM Unmer Malang

Pada Gambar 11 menjajikan pengujian posisi baut vertikal 2-4-11 menggunakan 3 baut dengan titik berat x.240;y.266. Besarnya diameter baut, pengerasan baut, koefisien gesek dan posisi sudut sangat berpengaruh terhadap besarnya momen torsi [6].

Tabel 2. Hasil penelitian pengujian baut [5]

\begin{tabular}{lccccccc}
\hline No & Posisi baut & A & B & C & D & E & F \\
\hline L1 & $2-6-10$ & 113 & $160: 240$ & 65 & 169 & 76.401 & 2 \\
L2 & $6-7-8$ & 113 & $240: 240$ & 55 & 143 & 64.701 & 8 \\
L3 & $2-4-11$ & 113 & $240: 266$ & 92 & 240 & 108.342 & 4 \\
\hline
\end{tabular}

Keterangan :

A = Luas Penampang baut $\left(\mathrm{mm}^{2}\right) \quad \mathrm{D}=$ Gaya dongkrak (kg-f)

$\mathrm{B}=$ Titik berat $(\mathrm{X}: \mathrm{Y})(\mathrm{mm}) \quad \mathrm{E}=$ Momen puntir $(\mathrm{kg}-\mathrm{mm})$

$\mathrm{C}=$ Tekanan dongkrak (bar) $\quad \mathrm{F}=$ Nomor baut putus

Tabel 2 menyajikan hasil pengujian dengan pemosisian tiga letak baut dan jarak pembebanan.

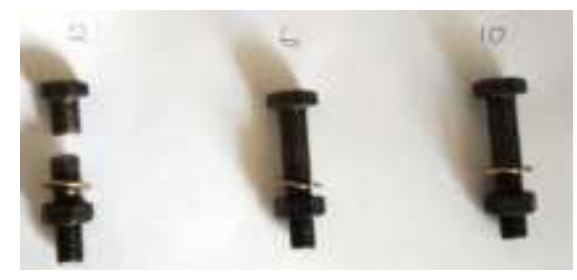

Gambar 12. Patahan pengujian baut vertikal 2-6-10

Sumber: Laboratorium proses produksi JTM Unmer Malang

Gambar 12 menyajikan model patahan yang terjadi akibat penekanan dongkrak 65 bar, gaya dongkrak $169 \mathrm{~kg}-\mathrm{f}$ dan momen puntir $76.401 \mathrm{~kg}-\mathrm{mm}$, terlihat terjadi puntiran baut pada nomor 2. Baut nomor 2 mengalami geser atau patah disebabkan tekanan yang diterima pada baut nomor 2 lebih besar dibandingkan pada baut nomor 6 dan 10 yang hanya mengalami pergeseran tetapi tidak sampai terjadi patahan.

Titik berat pada posisi vertikal yaitu pada sumbu $\mathrm{x}=160$ dan sumbu $\mathrm{y}=240$, sehingga radius berpengaruh terjadinya pergeseran yang mengakibatkan patah [3].

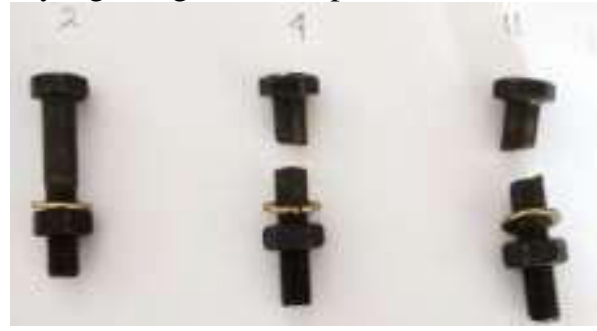

Gambar 13. Patahan pengujian baut horisontal 2-4-11 Sumber: Laboratorium proses produksi JTM Unmer Malang
Gambar 13 menyajikan model patahan yang terjadi akibat penekanan dongkrak 92 bar, gaya dongkrak 143 kg-f dan momen puntir $108.342 \mathrm{~kg}-\mathrm{mm}$, terlihat terjadi puntiran baut pada nomor 4 . baut nomor 4 mengalami geser atau patah disebab kan karena beban atau tekanan yang diterima pada baut 4 lebih besar dibandingkan pada baut nomor 2 dan 11 yang hanya mengalami pergeseran tetapi tidak sampai terjadi patahan.
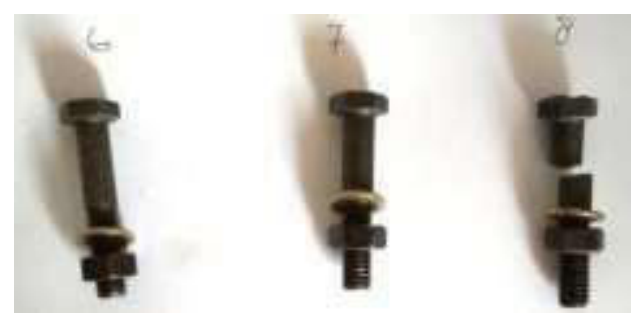

Gambar 14. Patahan pengujian baut horisontal 6-7-8 Sumber: Laboratorium proses produksi JTM Unmer Malang

Gambar 14 menyajikan model patahan yang terjadi akibat penekanan dongkrak 55 bar, gaya dongkrak 143 kg-f dan momen puntir $64.701 \mathrm{~kg}-\mathrm{mm}$, dengan jaraka pembebanan 240 $\mathrm{mm}$, pada baut nomor 8 terlihat terjadi puntiran patahan atau pergeseran disebabkan karena menerima beban dan tekanan yang besar terlebih dahulu dibandingkan pada baut nomor 6 dan 7 .

\section{Kesimpulan}

Posisi baut tiga sudut (Three Angle) 2-4-11 terjadi gaya geser yang lebih besar dibandingkan gaya geser yang terjadi pada posisi baut horisontal dan vertikal. Diperlukan tekanan dongkrak hingga 92,66 bar momen puntir 108.342 kg-mm), dengan jarak pembebanan terjadi pergeseran atau patahan pada baut. Melihat visual model patahan pada no 11 terjadi cracking torsion yang diakibatkan pembebanan maksimum.

\section{Ucapan Terimakasih}

Ucapan terimakasih (acknowledgement) diberikan kepada saudara Yanuar wibisono alumni JTM 2013 Universitas Merdeka Malang, yang telah banyak membantu dan bekerjasama dalam pelaksanaan penelitian ini.

\section{Referensi}

[1] Devi, C., Gunawarman dan M. Fadli., 2010, "Analisisegangan Baut Pengunci girth-gear kiln", Vol. 1 No. 33. Jurnal TEKNIKA Unand.,

[2] Darius Nama Lanan, 2017. "Analisa Patahan Baut Pada Sambungan Plat Baja Dengan Variasi Ring dan Plat Tambahan" Tugas Akhir, Teknik Mesin, Universitas Merdeka Malang

[3] Nofriady Handra dan Brazi 2011. "Pengaruh Posisi Baut Galvalis dan Stainless Steel Ditinjau dari Fracture Surface pada Sambungan Plat" Vol.2, No. 1 Jurnal Teknik Mesin. ITP

[4] Joseph E. Shigley, 1999."Perencanaan Teknik Mesin jilid 1". Edisi ke 4. Penerbit Erlangga Jakarta.

[5]. Yanuar Wibisono,2018. "Pengaruh posisi sambungan baut terhadap Gaya geser pada sambungan plat baja". Tugas Akhir Jurusan Teknik Mesin Universitas Merdeka Malang 
TRANSMISI Volume 16 Nomor 22020

[6] Akbar Pirmoz, Amir Saedi Daryan, Ahad Mazaheri, Hajar Ebrahim Darbandi,2008. "Behavior of bolted angle connections subjected to combined shear force and moment". Journal of Constructional Steel Research 64 436-446.

[7] Roozbeh kiamanesh,2011. "On the effects of circular bolt patterns on The behavior of the extended end-plate connections". Doctor Of Philosophy, The university of texas at arlington 